\title{
Hypomagnesemia in Hemodialysis Patients: Role of Proton Pump Inhibitors
}

\author{
Mohamad Alhosaini $^{\mathrm{a}}$ James S. Walter ${ }^{\mathrm{b}}$ Sanjay Singh ${ }^{\mathrm{b}, \mathrm{c}}$ Robert S. Dieter ${ }^{\mathrm{a}}$ \\ Annming Hsieh ${ }^{a}$ David J. Leehey ${ }^{\mathrm{a}}$ \\ Departments of a Medicine and ${ }^{\mathrm{b}}$ Research, Edward Hines Jr. Veterans Affairs Hospital, Hines, III., and \\ 'East-West University, Biological Sciences, Chicago, III., USA
}

\section{Key Words}

Magnesium · Hemodialysis · Proton pump inhibitors

\begin{abstract}
Background: Recent observations have associated hypomagnesemia with increased risk of cardiovascular morbidity and mortality in hemodialysis patients. Methods: We did a 3-month chart review of 62 chronic hemodialysis patients at a single US hospital. All were dialyzed using a dialysate [Mg] of $0.75-1.0 \mathrm{mEq} / \mathrm{l}$. Patients were divided into two groups: hypomagnesemic (mean predialysis plasma $[\mathrm{Mg}]<1.5$ $\mathrm{mEq} / \mathrm{l}$ ) and non-hypomagnesemic (mean predialysis plasma $[\mathrm{Mg}] \geq 1.5 \mathrm{mEq} / \mathrm{l})$. Results: All patients were male; mean age was $64.3 \pm 8.7$ years and the majority (73\%) diabetic. 24 patients (39\%) had hypomagnesemia and 38 (61\%) were not hypomagnesemic. There were no significant differences between the two groups in age, diabetes status, blood pressure, duration of dialysis, plasma calcium, phosphorus, albumin, intact parathyroid hormone (PTH), dialysis adequacy $(\mathrm{Kt} / \mathrm{V})$, or dietary protein intake (as estimated by normalized protein catabolic rate, $\mathrm{nPCR}$ ). However, use of proton pump inhibitors (PPIs) was significantly associated with hypomagnesemia (plasma [Mg] $1.48 \pm 0.16 \mathrm{mEq} / \mathrm{l}$ in the PPI group vs. $1.65 \pm 0.26 \mathrm{mEq} / \mathrm{l}$ in the non-PPI group, $\mathrm{p}=0.007$ ). Adjustment for age, diabetes status, duration of dialysis, plasma
\end{abstract}

albumin, Kt/V, nPCR, and diuretic use did not affect the association between PPI use and hypomagnesemia. Conclusions: Use of PPIs in patients dialyzed using a dialysate [Mg] of $0.75-1.0 \mathrm{mEq} / \mathrm{l}$ is associated with hypomagnesemia. We suggest monitoring plasma [Mg] in patients taking PPIs, with discontinuation of the medication if possible and/or adjustment of dialysate [Mg] to normalize plasma [Mg].

(c) 2014 S. Karger AG, Basel

\section{Introduction}

Patients with advanced chronic kidney disease and end-stage kidney disease have impaired magnesium excretion $[1,2]$. Since renal excretion is generally minimal, magnesium balance in hemodialysis patients depends on two main factors: oral magnesium intake/gastrointestinal absorption and dialysate magnesium concentration [Mg].

In recent years, dialysate $[\mathrm{Mg}]$ in the USA has generally been lower (ca. $0.75-1.0 \mathrm{mEq} / \mathrm{l}$ ) than that used in the past (ca. $1.5 \mathrm{mEq} / \mathrm{l}$ ) [3]. The reason for the present use of lower dialysate $[\mathrm{Mg}]$ is multifactorial. Several past studies have suggested that hypermagnesemia, by increasing total body and bone magnesium, may lead to worsening of renal osteodystrophy [4], delayed nerve conduction [5], and pruritus [6], and that lowering plasma [Mg] can im-

\section{KARGER}

E-Mail karger@karger.com

www.karger.com/ajn
(C) 2014 S. Karger AG, Basel

0250-8095/14/0393-0204\$39.50/0
D.J. Leehey

111-L, Veterans Affairs Hospital

Hines, IL 60141 (USA)

E-Mail dleehey@lumc.edu 
Table 1. Clinical characteristics of patients

\begin{tabular}{llcc}
\hline & $\begin{array}{l}\text { Hypomagnesemic } \\
\text { (plasma Mg }<1.5 \mathrm{mEq} / \mathrm{l}) \\
(\mathrm{n}=24)\end{array}$ & $\begin{array}{l}\text { Non-hypomagnesemic } \\
\text { (plasma Mg } \geq 1.5 \mathrm{mEq} / \mathrm{l}) \\
(\mathrm{n}=38)\end{array}$ & $\mathrm{p}$ \\
\hline Plasma magnesium, mEq/l & $1.37 \pm 0.10$ & $1.70 \pm 0.20$ & $<0.001$ \\
Age, years & $64.8 \pm 7.2$ & $64.0 \pm 9.6$ & 0.75 \\
Diabetes & $19 / 24(79 \%)$ & $26 / 38(68 \%)$ & 0.29 \\
Plasma calcium, mg/dl & $8.5 \pm 0.63$ & $8.5 \pm 0.52$ & 0.87 \\
Plasma phosphorus, mg/dl & $4.7 \pm 1.01$ & $4.8 \pm 1.12$ & 0.78 \\
Plasma intact PTH, pg/ml & $534 \pm 326$ & $559 \pm 542$ & 0.84 \\
Plasma albumin, g/dl & $3.2 \pm 0.42$ & $3.3 \pm 0.34$ & 0.37 \\
Kt/V & $1.39 \pm 0.32$ & $1.50 \pm 0.27$ & 0.17 \\
nPCR, g/kg/day & $0.77 \pm 0.18$ & $0.81 \pm 0.16$ & 0.36 \\
Predialysis systolic BP, mm Hg & $138 \pm 21$ & $140 \pm 17$ & 0.35 \\
Predialysis diastolic BP, mm Hg & $74 \pm 10$ & $74 \pm 12$ & 0.94 \\
Postdialysis systolic BP, mm Hg & $131 \pm 21$ & $132 \pm 17$ & 0.87 \\
Postdialysis diastolic BP, mm Hg & $70 \pm 9.1$ & $69 \pm 12$ & 0.88 \\
Duration of dialysis, years & $3.8 \pm 3.7$ & $3.2 \pm 3.1$ & 0.46 \\
Use of magnesium supplements & $0 / 24(0 \%)$ & $2 / 38(5 \%)$ & 0.25 \\
Use of diuretics & $7 / 24(29 \%)$ & $3 / 38(8 \%)$ & 0.027 \\
Use of PPIs & $16 / 24(67 \%)$ & $13 / 38(34 \%)$ & 0.013 \\
\hline
\end{tabular}

Table 2. Characteristics of PPI use

\begin{tabular}{llll}
\hline & $\begin{array}{l}\text { Hypomagnesemic } \\
(\text { plasma Mg }<1.5 \mathrm{mEq} / \mathrm{l})\end{array}$ & $\begin{array}{l}\text { Non-hypomagnesemic } \\
(\text { plasma Mg } \geq 1.5 \mathrm{mEq} / \mathrm{l})\end{array}$ & $\mathrm{p}$ \\
\hline Use of PPIs & $16 / 24(67 \%)$ & $13 / 38(34 \%)$ & 0.013 \\
Duration of PPI use, years & $6.7 \pm 2.3$ & $5.8 \pm 2.9$ & 0.35 \\
Dose of PPI, mg/day & $53 \pm 24$ & $40 \pm 24$ & 0.15 \\
\hline
\end{tabular}

prove these abnormalities [4-6]. More recently, use of magnesium as an inexpensive phosphate binder [7-11] and the possible role of high magnesium in adynamic bone disease [12] have led to use of a lower dialysate [Mg]. Whereas mild hypermagnesemia is expected with use of a dialysate $[\mathrm{Mg}]$ of $1.5 \mathrm{mEq} / \mathrm{l}[13-16]$, a dialysate $[\mathrm{Mg}]$ of $1.0 \mathrm{mEq} / \mathrm{l}$ has generally been associated with either normal plasma $[\mathrm{Mg}]$ or mild hypermagnesemia $[17,18]$. Lower dialysate $[\mathrm{Mg}]$ (i.e. $0.4-0.5 \mathrm{mEq} / \mathrm{l}$ ) has generally not resulted in hypomagnesemia in previous studies [1, $13,14,16,18]$.

We regularly monitor plasma $[\mathrm{Mg}]$ at our dialysis center, and previously reported hypomagnesemia in peritoneal dialysis patients using a low $(0.5 \mathrm{mEq} / \mathrm{l})$ dialysate [Mg] [19]. Recently, we have observed predialysis hypomagnesemia in our hemodialysis patients, which was of concern because of recent observations associating hypomagnesemia with increased risk of cardiovascular mor- bidity and mortality in this population [20-23]. We herein report the prevalence and investigate the possible mechanisms of hypomagnesemia in hemodialysis patients at a single center in the USA in whom a dialysate $[\mathrm{Mg}]$ of $0.75-1.0 \mathrm{mEq} / \mathrm{l}$ was utilized.

\section{Methods}

We reviewed the computerized charts of all patients $(n=62)$ undergoing chronic hemodialysis at Edward Hines Jr. Veterans Affairs Hospital, Hines, Ill., USA during the 3-month period between December 1, 2012 and February 28, 2013. This study was approved by the Institutional Review Board at Hines VA Hospital, and all study procedures were in accord with the Declaration of Helsinki and its revisions. Informed consent was not deemed necessary due to the retrospective observational nature of the study. The electrolyte composition of the dialysate utilized was as follows (in $\mathrm{mEq} / \mathrm{l}$ ): sodium 137 , potassium $2-4$, chloride 105 , acetate 4 , bicarbonate 33 , calcium 2.5 , and magnesium $0.75-1.0 .50$ patients 
were treated with a dialysate $[\mathrm{Mg}]$ of $0.75 \mathrm{mEq} / \mathrm{l}$ and 11 patients with a dialysate $[\mathrm{Mg}]$ of $1.0 \mathrm{mEq} / \mathrm{l} ; 1$ patient was dialyzed against both concentrations at different times during the study period. As there was no significant difference in plasma $[\mathrm{Mg}]$ between patients dialyzed with a 0.75 versus $1.0 \mathrm{mEq} / \mathrm{l}$ bath $(1.90 \pm 0.30$ vs. $1.82 \pm 0.15, p=0.42$ ), analyses were not separately performed based on dialysate $[\mathrm{Mg}]$. All patients received three times weekly hemodialysis and had plasma [Mg] measured monthly. Patients were divided into two groups based on the mean of their plasma magnesium levels: hypomagnesemic (mean predialysis plasma $[\mathrm{Mg}]<1.5 \mathrm{mEq} / \mathrm{l}$ ) and non-hypomagnesemic (mean predialysis plasma $[\mathrm{Mg}] \geq 1.5 \mathrm{mEq} / \mathrm{l})$.

We then determined the possible associations of plasma $[\mathrm{Mg}]$ with age, presence of diabetes, duration of dialysis, and mean values of plasma calcium, phosphorus, albumin, intact parathyroid hormone $(\mathrm{PTH})$, dialysis adequacy $(\mathrm{Kt} / \mathrm{V})$, and dietary protein intake (as estimated by normalized protein catabolic rate, nPCR), all of which were measured monthly during the 3-month study period. We also examined pre- and postdialysis blood pressures using data from the first three dialysis sessions of each month, i.e. those closest in time to the monthly plasma magnesium measurements. Medications known to affect plasma [Mg], such as proton pump inhibitors (PPIs), diuretics, and magnesium supplements, were also compared. Comparisons were made using $t$ test for continuous data or $\chi^{2}$ for categorical data. Linear regression analysis was utilized to adjust for potential confounding variables when using a continuous dependent variable. Logistic regression analysis was utilized to adjust for potential confounders when a dichotomous outcome was employed. Data were expressed as mean \pm $\mathrm{SD}$. A p value $<0.05$ was considered significant.

\section{Results}

The mean age of our 62 hemodialysis patients was 64.3 \pm 8.7 years. All patients were male and the majority $(73 \%)$ diabetic. 24 patients (39\%) had hypomagnesemia (mean plasma $[\mathrm{Mg}]<1.5 \mathrm{mEq} / \mathrm{l}$; range $1.15-1.48)$ and $38 \mathrm{pa}-$ tients $(61 \%)$ were not hypomagnesemic (mean plasma $[\mathrm{Mg}] \geq 1.5 \mathrm{mEq} / \mathrm{l}$; range $1.5-2.25)$. As shown in table 1 , there were no significant differences between the two groups in age, presence of diabetes, duration of dialysis, or mean values for plasma calcium, phosphorus, albumin, intact $\mathrm{PTH}, \mathrm{Kt} / \mathrm{V}$ or nPCR. Pre- and postdialysis systolic and diastolic blood pressures were also not different between the two groups. Diuretic use was uncommon (only 10 of 62 patients were taking furosemide), but was significantly more common in the hypomagnesemic group. Only 2 patients received oral magnesium supplements.

Use of PPIs was significantly associated with hypomagnesemia (table 1). Use of PPIs was common, with almost half our patients being prescribed these medications. Most patients $(\mathrm{n}=22)$ were treated with omeprazole $(20-80 \mathrm{mg} /$ day $)$, with fewer patients $(\mathrm{n}=7)$ treated

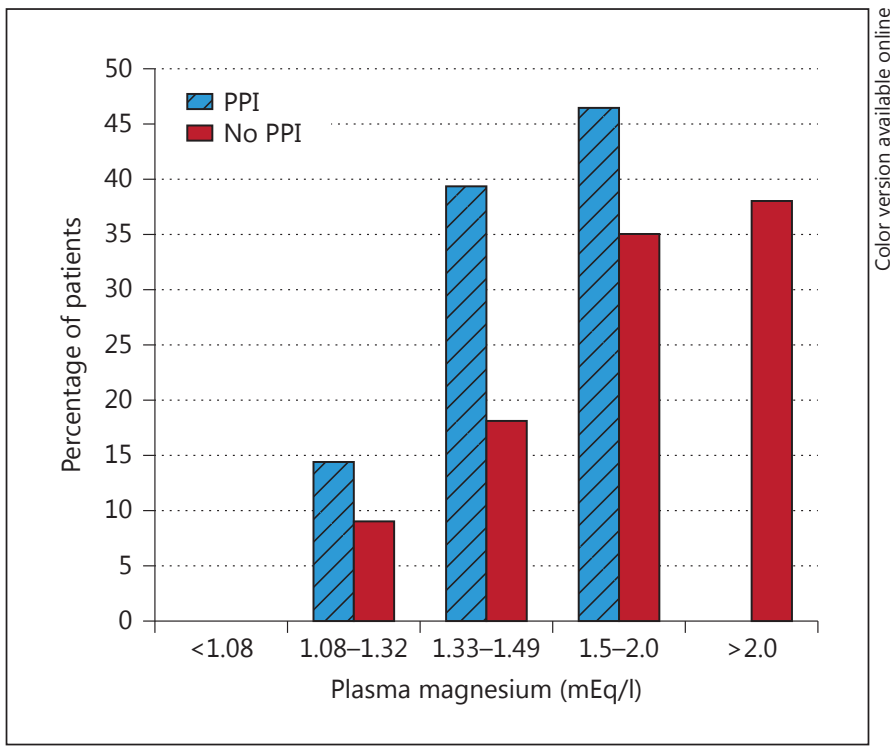

Fig. 1. Relationship between PPI use and plasma $[\mathrm{Mg}]$. It can be seen that the percentage of patients with both mild and more substantial hypomagnesemia was higher in patients taking PPIs.

with pantoprazole (40-80 mg/day). Duration of PPI use ranged from 1 to 9 years; neither duration nor dose was significantly different between the hypomagnesemic and non-hypomagnesemic groups (table 2). When analyzed as a continuous variable, plasma $[\mathrm{Mg}]$ was $1.48 \pm 0.16$ $\mathrm{mEq} / \mathrm{l}$ in patients taking PPIs and $1.65 \pm 0.26 \mathrm{mEq} / \mathrm{l}$ in patients not taking these medications $(\mathrm{p}=0.007)$. The relationship between PPI use and plasma $[\mathrm{Mg}]$ is shown in figure 1. It can be seen that the percentage of patients with both mild (plasma $[\mathrm{Mg}] 1.33-1.49 \mathrm{mEq} / \mathrm{l}$ ) and more substantial (plasma [Mg] 1.08-1.32 mEq/l) hypomagnesemia was higher in patients taking PPIs. No patient had a plasma $[\mathrm{Mg}]<1.08 \mathrm{mEq} / \mathrm{l}$.

Using linear regression analysis with plasma $[\mathrm{Mg}]$ as the dependent variable, PPI use was significantly associated with plasma $[\mathrm{Mg}](\mathrm{p}=0.008)$ after adjustment for age, diabetes status, duration of dialysis, plasma albumin, $\mathrm{Kt} / \mathrm{V}$, nPCR, and diuretic use. Logistic regression analysis was also performed to see if variables other than PPI use were associated with hypomagnesemia. After adjustment for age, diabetes status, duration of dialysis, plasma albu$\mathrm{min}, \mathrm{Kt} / \mathrm{V}$, nPCR, and diuretic use, PPI use remained significantly associated with hypomagnesemia (table 3 ).

In order to exclude the possibility that the relationship between PPI use and hypomagnesemia might be confounded by other clinical variables, logistic regression analysis was also performed with PPI use as the outcome. 
Table 3. Factors associated with hypomagnesemia: logistic regression analysis

\begin{tabular}{llll}
\hline & OR & $95 \%$ CI & p \\
\hline $\begin{array}{l}\text { Unadjusted } \\
\quad \text { PPI use }\end{array}$ & & & \\
$\begin{array}{l}\text { Adjusted } \\
\quad \text { PPI use }\end{array}$ & 3.85 & $1.30-11.3$ & 0.015 \\
$\quad$ Diuretic use & 4.20 & $1.16-15.2$ & 0.029 \\
$\quad$ Duration of dialysis & 6.25 & $1.05-37.1$ & 0.044 \\
$\quad$ Dialytic urea clearance, Kt/V & 1.19 & $0.98-1.46$ & 0.09 \\
$\quad$ Diabetes & 1.84 & $0.01-2.19$ & 0.17 \\
$\quad$ Plasma albumin & 0.65 & $0.11-3.61$ & 0.40 \\
$\quad$ Protein intake & 2.29 & $0.04-118$ & 0.64 \\
$\quad$ Age & 1.00 & $0.92-1.09$ & 0.99 \\
\hline
\end{tabular}

After adjustment for age, diabetes status, duration of dialysis, plasma albumin, Kt/V, nPCR, and diuretic use, hypomagnesemia remained significantly associated with PPI use ( $\mathrm{p}=0.03)$; none of the other variables was associated with PPI use.

\section{Discussion}

The most important observation made in our study was the significant association between use of PPIs and hypomagnesemia. In the event of decreased oral magnesium intake, normally there is increased active intestinal absorption of magnesium, which is mediated by the transient receptor potential melastatin-6 (TRPM6) and -7 (TRPM7) transport system. This will mitigate against the development of hypomagnesemia when dietary intake and thus intestinal luminal concentrations are low [24]. It has recently been discovered that PPIs impair intestinal magnesium absorption by disrupting active transport by TRPM 6/7 channels [24], thus impairing the adaptive intestinal response to a decrease in dietary magnesium intake. The mechanism involves a decrease in intestinal $\mathrm{pH}$, which in turn is thought to decrease the TRPM 6/7 affinity to magnesium and impair its absorption [25]. Hypomagnesemia has been reported to develop mainly after chronic PPI ingestion for many years, with no obvious dose relationship [24]. The majority of non-dialysis patients on these drugs do not develop hypomagnesemia; indeed, this effect was only seen in a subgroup in which there was concomitant use of diuretics [26]. In our study, nearly $50 \%$ of the patients were prescribed PPIs, and there was a highly significant relationship between plasma
$[\mathrm{Mg}]$ and PPI use. Overall, two thirds of patients with hypomagnesemia were taking PPIs whereas only a third of non-hypomagnesemic patients were taking these medications.

Dialysate magnesium losses due to the relatively low dialysate $[\mathrm{Mg}]$ employed may also have contributed to hypomagnesemia. Coburn et al. [1] first reported the effect of low dialysate $[\mathrm{Mg}](0.5 \mathrm{mEq} / \mathrm{l})$ in hemodialysis patients. In comparison to patients dialyzed using a dialysate $[\mathrm{Mg}]$ of $1.5 \mathrm{mEq} / \mathrm{l}$, predialysis [Mg] was substantially lower but still generally in the normal range (1.4-2.1 $\mathrm{mEq} / \mathrm{l})$. Using a similarly low $(0.5 \mathrm{mEq} / \mathrm{l})$ dialysate $[\mathrm{Mg}]$, Gonella et al. [13] reported predialysis [Mg] of $1.57 \pm 0.05$ $\mathrm{mEq} / \mathrm{l}$ (range 1.16-1.82) with $4 / 12$ (33\%) of patients having a predialysis $[\mathrm{Mg}]$ of $<1.5 \mathrm{mEq} / \mathrm{l}$. Using an even lower $(0.4 \mathrm{mEq} / \mathrm{l})$ dialysate $[\mathrm{Mg}]$ for a duration of 4 months, Nilsson et al. [14] reported a mean predialysis [Mg] of $1.86 \pm 0.48 \mathrm{mEq} / \mathrm{l}$. The range of values was not given, but based on the reported variance in their data, probably no more than $20 \%$ had plasma $[\mathrm{Mg}]<1.5 \mathrm{mEq} / \mathrm{l}$. Saha et al. [18] compared 0.5 versus $1.0 \mathrm{mEq} / \mathrm{l}$ dialysate $[\mathrm{Mg}]$ in patients on hemodialysis for greater than 3 months. Mean predialysis $[\mathrm{Mg}]$ was not significantly different between the groups ( $1.86 \pm 0.36$ vs. $2.02 \pm 0.38 \mathrm{mEq} / \mathrm{l})$; hypomagnesemia was uncommon, with only $2 / 47$ patients having predialysis $[\mathrm{Mg}]<1.5 \mathrm{mEq} / \mathrm{l}$. Finally, in the largest reported study, Navarro et al. [17] studied 110 patients dialyzed for 8-127 months using a dialysate $[\mathrm{Mg}]$ of $1.0 \mathrm{mEq} / \mathrm{l}$. Predialysis $[\mathrm{Mg}]$ was $2.33 \pm 0.4 \mathrm{mEq} / \mathrm{l}$. Based on the observed variance, very few patients had predialysis $[\mathrm{Mg}]$ $<1.5 \mathrm{mEq} / \mathrm{l}$. Taken together, these data suggest that predialysis hypomagnesemia may occur in up to one third of patients when a very low $(0.4-0.5 \mathrm{mEq} / \mathrm{l}$ dialysate $[\mathrm{Mg}])$ is used but is decidedly uncommon when a dialysate $[\mathrm{Mg}]$ of $1.0 \mathrm{mEq} / \mathrm{l}$ is employed. Although not previously reported, it would be predicted that probably no more than $10-20 \%$ of patients dialyzed using a dialysate $[\mathrm{Mg}]$ of 0.75 $\mathrm{mEq} / \mathrm{l}$ would have a predialysis plasma $[\mathrm{Mg}]$ of $<1.5$ $\mathrm{mEq} / \mathrm{l}$. This contrasts with the $39 \%$ prevalence of hypomagnesemia observed in our patients using a dialysate $[\mathrm{Mg}]$ of $0.75-1.0 \mathrm{mEq} / \mathrm{l}$. The higher than expected prevalence of hypomagnesemia in our patients is likely explained by PPI use.

Magnesium in the plasma exists in the ionized (unbound) form as well as bound to plasma proteins, predominantly albumin. The ionized fraction usually represents about $30 \%$ of the total magnesium. Hemodialysis patients have been reported to have both lower [15] and higher [27] ionized fractions than in non-dialysis patients. Since we measured total and not ionized plasma 
magnesium, we cannot entirely exclude the possibility of variable ionized $[\mathrm{Mg}]$ among our patients. Patients with hypomagnesemia could have had decreased binding of magnesium to albumin in the plasma, leading to a higher concentration gradient between plasma and dialysate in the hypomagnesemia group. We believe this to be unlikely though, as the plasma albumin levels were similar in both groups.

Magnesium is known to play an important role in bone metabolism, but its precise role in hemodialysis patients remains undefined. The calcium-sensing receptor in the parathyroid glands is affected by magnesium, and both hypermagnesemia and severe hypomagnesemia can suppress PTH [28-32]. In dialysis patients, many studies have shown an association between lower dialysate [14, $33-35]$ or serum $[17,36,37]$ magnesium and higher PTH. However, similar to our findings, Cho et al. [38] and O'Donovan et al. [39] also failed to show any association between dialysate magnesium and PTH.

Hypomagnesemia typically refers to low plasma $[\mathrm{Mg}]$ because this measurement has long been readily available. Because magnesium is mostly an intracellular cation, some have questioned whether plasma levels accurately reflect intracellular magnesium concentrations. We did not measure intracellular magnesium concentrations in our patients. However, from a clinical standpoint, it has been suggested that in a patient with suspected magnesium deficiency, low plasma $[\mathrm{Mg}]$ is sufficient to confirm the diagnosis [40].

The samples size of our study is too small to make any statement about cardiovascular or overall clinical outcomes in our patients. Nevertheless, hypomagnesemia may have important clinical implications. Over the long term, chronic hypomagnesemia can increase vascular calcification in hemodialysis patients [41, 42]. In addition, there is concern about the potential hemodynamic and cardiovascular effects of acutely lowering the plasma magnesium level during hemodialysis [43, 44]. Most importantly, serum magnesium has been recently reported to be a significant predictor of mortality in advanced renal disease patients [20-23]. In a study of 515 hemodialysis patients in Japan, there was a higher risk for death in patients with lower baseline serum magnesium than those with serum magnesium $>2.77 \mathrm{mg} / \mathrm{dl}(2.3 \mathrm{mEq} / \mathrm{l})$ [20]. In another study in $283 \mathrm{CKD}$ patients, higher cardiovascular mortality in those with serum magnesium $<2.05 \mathrm{mg} / \mathrm{dl}$ $(1.7 \mathrm{mEq} / \mathrm{l})$ was observed [21]. Both low serum $[\mathrm{Mg}]$ and high serum calcium were independently associated with malnutrition, inflammation, arterial stiffening and risk of death [22]. Another very recent study, again from Japan, also reported hypomagnesemia to be a risk factor for mortality in hemodialysis patients [23].

These observational studies indicate the need for interventional studies to confirm a cause-effect relationship between hypomagnesemia and adverse outcomes in hemodialysis patients. However, at the present state of knowledge, it would appear prudent to avoid hypomagnesemia in hemodialysis patients. In particular, we suggest monitoring plasma $[\mathrm{Mg}]$ in patients taking PPIs, with discontinuation of the medication if possible and/or adjustment of dialysate $[\mathrm{Mg}]$ to normalize plasma $[\mathrm{Mg}]$.

\section{Acknowledgements}

We acknowledge the assistance and support of Subhash Popli, MD, Mohamed Rahman, MD, Nicholas Burge, PharmD, Cheryl Cooper, MS, MPH, and Holly Kramer, MD, MPH.

\section{Disclosure Statement}

The authors have no conflicts of interest to disclose.

\section{References}

1 Coburn JW, Popovtzer MM, Massry SG, Kleeman CR: The physicochemical state and renal handling of divalent ions in chronic renal failure. Arch Intern Med 1969;124:302-311.

$\checkmark 2$ Massry SG: Magnesium homeostasis in patients with renal failure. Contrib Nephrol. Basel, Karger, 1984, vol 38, pp 175-184.

3 Cunningham J, Rodríguez M, Messa P: Magnesium in chronic kidney disease stages 3 and 4 and in dialysis patients Clin Kidney J 2012; 5(suppl 1):i39-i51.
4 Gonella M, Ballanti P, Della Rocca C, et al: Improved bone morphology by normalizing serum magnesium in chronically hemodialyzed patients. Miner Electrolyte Metab 1988; 14:240-245.

5 Fleming LW, Lenman JAR, Stewart WK: Effect of magnesium on nerve conduction velocity during regular dialysis treatment. J Neurol Neurosurg Psychiatry 1972;35:342355 .
6 Graf H, Kovarik I, Stummvoll H: Disappearance of uremic pruritus after lowering dialysate magnesium concentration. $\mathrm{Br}$ Med J 1979;2:1478-1479.

7 Delmez JA, Kelber J, Norword KY, et al: Magnesium carbonate as a phosphorus binder: a prospective, controlled, crossover study. Kidney Int 1996;49:163-167.

8 Spiegel DM, Farmer B, Smits G, et al: Magnesium carbonate is an effective phosphate binder for chronic hemodialysis patients: a pilot study. J Ren Nutr 2007;17:416-422. 
$\checkmark 9$ Spiegel DM: The role of magnesium binders in chronic kidney disease. Semin Dial 2007; 20:333-336.

10 Tzanakis IP, Papadaki AN, Wei M, et al: Magnesium carbonate for phosphate control in patients on hemodialysis. A randomized controlled trial. Int Urol Nephrol 2008;40:193201.

11 De Francisco AL, Leidig M, Covic AC, et al: Evaluation of calcium acetate/magnesium carbonate as a phosphate binder compared with sevelamer hydrochloride in haemodialysis patients: a controlled randomized study (CALMAG study) assessing efficacy and tolerability. Nephrol Dial Transplant 2010;25: 3707-3717.

12 Navarro JF, Macia ML, Gallego E, et al: Serum magnesium concentration and PTH levels. Is long-term chronic hypermagnesemia a risk factor for adynamic bone disease? Scand J Urol Nephrol 1997;31:275-280.

13 Gonella M, Buzzigoli G, Bencivelli W, Bartolini V, Betti G: The determination of whole blood magnesium concentration in uremics on chronic dialysis. Nephron 1981;28:88-89.

14 Nilsson P, Johansson SG, Danielson BG: Magnesium studies in hemodialysis patients before and after treatment with low dialysate magnesium. Nephron 1984;37:25-29.

$\checkmark 15$ Truttmann AC, Faraone R, Von Vigier RO, Nuoffer JM, Pfister R, Bianchetti MG: Maintenance hemodialysis and circulating ionized magnesium. Nephron 2002;92:616-621.

16 Kelber J, Slatopolsky E, Delmez JA: Acute effects of different concentrations of dialysate magnesium during high-efficiency dialysis. Am J Kidney Dis 1994;24:453-460.

17 Navarro JF, Mora C, Jimenez A, Torres A, Macia M, Garcia J: Relationship between serum magnesium and parathyroid hormone levels in hemodialysis patients. Am J Kidney Dis 1999;34:43-48.

-18 Saha H, Harmoinen A, Pietila K, Morsky P, Pasternack A: Measurement of serum ionized versus total levels of magnesium and calcium in hemodialysis patients. Clin Nephrol 1996; 46:326-331.

-19 Ejaz AA, McShane AP, Gandhi VC, Leehey DJ, Ing TS: Hypomagnesemia in continuous ambulatory peritoneal dialysis patients dialyzed with a low-magnesium peritoneal dialysis solution. Perit Dial Int 1995;15:61-64.

20 Ishimura E, Okuno S, Yamakawa T, Inaba M, Nishizawa Y: Serum magnesium concentration is a significant predictor of mortality in maintenance hemodialysis patients. Magnes Res 2007;20:237-244.
21 Kanbay M, Yilmaz MI, Apetrii M, et al: Relationship between serum magnesium levels and cardiovascular events in chronic kidney disease patients. Am J Nephrol 2012;36:228 237.

22 Markaki A, Kyriazis J, Stylianou K, et al: The role of serum magnesium and calcium on the association between adiponectin levels and all-cause mortality in end-stage renal disease patients. PLoS One 2012;7:e52350.

23 Sakaguchi Y, Fujii N, Shoji T, Hayashi T, Rakugi H, Isaka Y: Hypomagnesemia is a significant predictor of cardiovascular and noncardiovascular mortality in patients undergoing hemodialysis. Kidney Int 2014;85:174181.

24 Perazella MA: Proton pump inhibitors and hypomagnesemia: a rare but serious complication. Kidney Int 2013;83:553-556.

25 Bai J, Hausman E, Lionberger R, Zhang X: Modeling and simulation of the effect of proton pump inhibitors on magnesium homeostasis. 1. Oral absorption of magnesium. Mol Pharm 2012;9:3495-3505.

26 Danziger J, William JH, Scott DJ, et al: Proton-pump inhibitor use is associated with low serum magnesium concentrations. Kidney Int 2013;83:692-699.

27 Walser M: The separate effects of hyperparathyroidism. Hypercalcemia of malignancy, renal failure, and acidosis on the state of calcium, phosphate, and other ions in plasma. J Clin Invest 1962;41:1454-1471.

28 Massry SG, Coburn JW, Kleeman CR: Evidence for suppression of parathyroid gland activity by hypermagnesemia. J Clin Invest 1970;49:1619-1629.

-29 Ferment O, Garnier PE, Touitou Y: Comparison of the feedback effect of magnesium and calcium on parathyroid hormone secretion in man. J Endocrinol 1987;113:117-122.

30 Anast CS, Mohs JM, Kaplan SL, Burns TW: Evidence for parathyroid failure in magnesium deficiency. Science 1972;177:606-608.

31 Duran MJ, Borst GC III, Osburne RC, Eil C: Concurrent renal hypomagnesemia and hypoparathyroidism with normal parathormone responsiveness. Am J Med 1984;76: 151-154.

32 Mennes P, Rosenbaum R, Martin K, Slatopolsky E: Hypomagnesemia and impaired parathyroid hormone secretion in chronic renal disease. Ann Intern Med 1978;88:206-209.

33 Sanchez C, Lopez-Barea F, Sanchez-Cabezudo J, et al: Low vs. standard calcium dialysate in peritoneal dialysis: differences in treatment, biochemistry and bone histomorphometry. A randomized multicentre study. Nephrol Dial Transplant 2004;19:1587-1593.
34 Pletka P, Bernstein DS, Hampers CL, Merrill JP, Sherwood LM: Relationship between magnesium and secondary hyperparathyroidism during long-term hemodialysis. Metabolism 1974;23:619-630.

35 Parsons V, Papapoulos SE, Weston MJ, Tomlinson S, O'Riordan JL: The long-term effect of lowering dialysate magnesium on circulating parathyroid hormone in patients on regular haemodialysis therapy. Acta Endocrinol (Copenh) 1980;93:455-460.

36 Wei M, Esbaei K, Bargman JM, Oreopoulos DG: Inverse correlation between serum magnesium and parathyroid hormone in peritoneal dialysis patients: a contributing factor to adynamic bone disease? Int Urol Nephrol 2006;38:317-322

37 Navarro JF, Mora C, Macia M, Garcia J: Serum magnesium concentration is an independent predictor of parathyroid hormone levels in peritoneal dialysis patients. Perit Dial Int 1999;19:455-461.

- 38 Cho MS, Lee KS, Lee YK, et al: Relationship between the serum parathyroid hormone and magnesium levels in continuous ambulatory peritoneal dialysis (CAPD) patients using low magnesium peritoneal dialysate. Korean J Intern Med 2002;17:114-121.

-39 O’Donovan R, Baldwin D, Hammer M, Moniz C, Parsons V: Substitution of aluminium salts by magnesium salts in control of dialysis hyperphosphataemia. Lancet 1986;1: 880-882.

40 Pham PC, Pham P-MT, Pham SV, Miller JM Pham PT: Hypomagnesemia in patients with type 2 diabetes. Clin J Am Soc Nephrol 2007; 2:366-373.

41 Spiegel DM, Farmer B: Long-term effects of magnesium carbonate on coronary artery calcification and bone mineral density in hemodialysis patients: a pilot study. Hemodial Int 2009;13:453-459.

42 Turgut F, Kanbay M, Metin MR, et al: Magnesium supplementation helps to improve carotid intima media thickness in patients on hemodialysis. Int Urol Nephrol 2008;40: 1075-1082.

-43 Kyriazis J, Kalogeropoulou K, Bilirakis L, et al Dialysate magnesium level and blood pressure. Kidney Int 2004;66:1221-1231.

44 Elsharkawy M, Youssef A, Zayoon M: Intradialytic changes of serum magnesium and their relation to hypotensive episodes in hemodialysis patients on different dialysates. Hemodial Int 2006;10:S16-S23. 